\title{
Subtask 1.12 - Solid-Phase Microextraction (SPME) Coupled with Optical Spectroscopy for Near Real-Time Determination of Fuel and Related Pollutants in Water
}

\section{Samples}

\author{
Semi-Annual Report \\ January 1 -June 30, 1996
}

RECEIVED

AUG 111997

OSTI

Work Performed Under Contract No.: DE-FC21-93MC30097

For

U.S. Department of Energy

Office of Fossil Energy

Federal Energy Technology Center

Morgantown Site

P.O. Box 880

Morgantown, West Virginia 26507-0880

By

Energy and Environmental Research Center

University of North Dakota

P. O. Box 9018

Grand Forks, North Dakota 58202-9018 


\section{Disclaimer}

This report was prepared as an account of work sponsored by an agency of the United States Government. Neither the United States Government nor any agency thereof, nor any of their employees, makes any warranty, express or implied, or assumes any legal liability or responsibility for the accuracy, completeness, or usefulness of any information, apparatus, product, or process disclosed, or represents that its use would not infringe privately owned rights. Reference herein to any specific commercial product, process, or service by trade name, trademark, manufacturer, or otherwise does not necessarily constitute or imply its endorsement, recommendation, or favoring by the United States Government or any agency thereof. The views and opinions of authors expressed herein do not necessarily state or reflect those of the United States Government or any agency thereof. 


\section{TABLE OF CONTENTS}

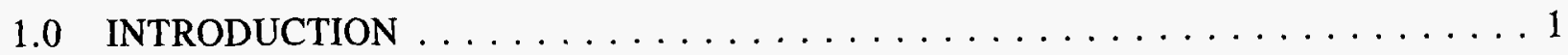

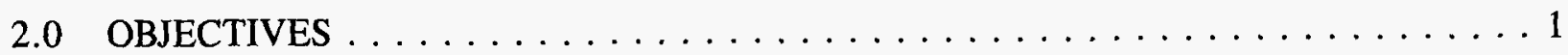

2.1 Development of a New SPME/UV Method for Determining Aromatic Fuel

Components in Water . . . . . . . . . . . . . . . . . 2

2.2 Sorbent Evaluation and Construction of Simple and Robust Sorbent Coupons . . . . 3

\section{LIST OF TABLES}

1 Equilibration Data for Selected Aromatic Compounds $\ldots \ldots \ldots \ldots \ldots \ldots \ldots$

2 Calibration Data for Selected Aromatic Compounds with SPME . . . . . . . . . 4

3 Detection Limits of Selected Aromatic Compounds with and Without SPME . . . . . 5

4 Detection Limits with and Without SPME for Various Fuels $\ldots \ldots \ldots \ldots \ldots \ldots$

5 Recovery Data for Unleaded Gasoline, JP4 and \#1 Diesel Fuel from

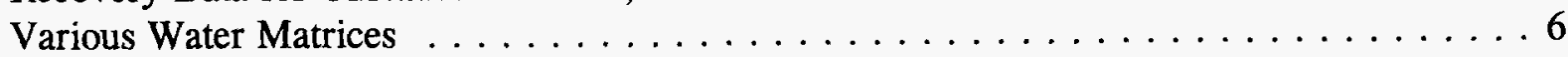




\section{SUBTASK 1.12 - SOLID-PHASE MICROEXTRACTION (SPME) COUPLED WITH OPTICAL SPECTROSCOPY FOR NEAR REAL-TIME DETERMINATION OF FUEL AND RELATED POLLUTANTS IN WATER SAMPLES}

\subsection{INTRODUCTION}

The measurement of organic pollutants in water requires that samples be collected, transported to a laboratory, extracted (usually with large volumes of hazardous chlorinated solvents), and analyzed using chromatographic techniques. Such limitations make rapid determinations in the field (e.g., for emergency response and/or for survey investigations) very expensive, with analytical turnaround times requiring several days. Similar limitations exist for the collection and analysis of organic pollutants in air. An alternative approach is being developed at the Energy \& Environmental Research Center (EERC) that has been demonstrated to yield good sensitivities (ppb to $\mathrm{ppm}$ ) and be easily adapted for rapid ( $<30$ minutes) and inexpensive field surveys. This new approach is based on the preconcentration of organic pollutants in optically clear sorbent media followed by measurement with either ultraviolet spectroscopy (UV) or Fourier transform infrared spectrometry (FT-IR). Initial investigations using sorbent media including methylsilicone gums (for UV spectroscopy) and "Parafilm" (for FT-IR) have shown that quantitative determinations of aromatic fuel components such as benzene and alkyl benzenes (BTEX) can be achieved using UV spectrometry. Quantitative determinations of common solvents (e.g., chloroform and other chlorinated solvents) can be achieved using FT-IR. Sample concentration and spectroscopic steps can be performed in a few minutes using the combination of solid-phase sorption followed by spectroscopic measurements. This preliminary work has demonstrated that the approach can yield low ppm to low ppb detection limits for organic pollutants in water without the negative influences of water matrix components (e.g., dissolved humic material) that prohibit the use of direct spectroscopic measurements. A good potential for real-time air monitoring of organic pollutants also exists. Additional advantages of the technique are that no organic solvents are used and that development of simple (and very inexpensive) "dipstick" devices should be possible that can be used with conventional (and portable) spectroscopic instrumentation.

This approach provides spectroscopic information to aid in compound-class determination, and by proper combination of the sorbent selectivity and the spectroscopy, it should be possible to focus on certain target compounds for specific determinations. However, given the great need for simple, cheap, fast, and solvent-free field methods, this project will focus on developing the method as a rapid survey method to be used either in the lab or in the field.

\subsection{OBJECTIVES}

The objectives of this subtask include the following:

- Evaluate the use of additional film-type sorbent media for spectroscopic clarity and sorption characteristics for organic pollutants related to fuel processing (e.g., fuel components, PAHs [polycyclic aromatic hydrocarbons], PCBs [polychlorinated 
biphenyls], chlorinated solvents). This task will utilize both UV and FT-IR spectroscopy as detection methods.

- Construct prototype dipstick devices and demonstrate their analytical capabilities.

- Produce accomplishments.

\subsection{Development of a New SPME/UV Method for Determining Aromatic Fuel Components in Water}

The preliminary investigations with OV-1 sorbent material (polydimethylsiloxane) and UV detection were promising enough that further development of the system was performed (in conjunction with a parallel project supported by the Environmental Protection Agency [EPA]). A method was developed to cast $2 \times 4 \times 10 \mathrm{~mm}$ "chips" of the sorbent phase which could then be inserted into a standard UV cell for the determination of absorbed analytes. For UV spectroscopy, the OV-1 sorbent is particularly well suited because it causes little loss of the UV light (mostly from light scattering), even with the 2 -mm-thick sorbent path. In addition, OV-1 is an excellent sorbent for nonpolar organics (such as the aromatic components of fuels) from water. Finally, OV1 is the same sorbent phase used for the gas chromatographic methods (which use a commercially available syringe-mounted sorbent), which allows our results to be compared to those determined by independent solid-phase extraction methods. With this system, the extraction of organic pollutants from water is performed by simply placing a sorbent chip into a water sample and shaking the sample for several minutes. The concentrations of absorbed aromatics are then determined using UV spectroscopy. The time required for absorption from the water depends on the thickness of the sorbent chip. As shown in Table 1, lower molecular weight aromatics (e.g., toluene) come to equilibrium in ca. 30 minutes, while higher molecular aromatics (e.g., naphthalene) require longer sorption times. However, it was determined that quantitative determinations could be performed even if the time used for sorption was shorter than that required for equilibrium (as long as the sorption time was constant). Therefore, all future sorptions of the pollutants from water were performed for 45 minutes.

The quantitative characteristics of the SPME/UV method for several common fuel components from spiked water are shown in Table 2. Note that all components can be determined over two orders of magnitude in concentration with excellent linearity. The effect of using the SPME concentration step compared to simply determining the organics in water solution by UV is shown in Table 3. Note that for all organics tested, using the OV-1 sorbent chip to preconcentrate the organics increases the sensitivity of the method by two orders of magnitude so that the detection limit for individual aromatic pollutants is typically in the low $\mathrm{ppb}(\mu \mathrm{g} / \mathrm{L})$ range.

It should be noted that an additional (and very important) advantage of using the SPME preconcentration step with the OV-1 chip is that the OV-1 sorbent does not concentrate the more polar matrix organics (such as dissolved humic materials) that are commonly found in surface waters. Since these matrix materials generally have very high UV absorbances, the analysis of fuel aromatics in water is not possible without the selectivity of the OV-1 sorbent chip. The SPME/UV method has also been tested on real-world surface waters contaminated with gasoline, JP-4 jet fuel, 
and diesel fuel. As shown in Table 4, the jet fuel and No. 1 diesel fuels could not be detected by direct UV measurements (no SPME preconcentration), even at very high concentrations, and the

\section{TABLE 1}

Equilibration Data for Selected Aromatic Compounds

\begin{tabular}{|c|c|c|}
\hline Compound & $\begin{array}{c}\text { Equilibration } \\
90 \%\end{array}$ & $\begin{array}{c}\text { Time, min. } \\
100 \%\end{array}$ \\
\hline Benzene & 20 & 30 \\
\hline Toluene & 20 & 30 \\
\hline Ethylbenzene & 20 & 30 \\
\hline$o$-Xylene & 30 & 45 \\
\hline$m$-Xylene & 25 & 40 \\
\hline$p$-Xylene & 30 & 45 \\
\hline 1-Methyl-3-ethylbenzene & 40 & 50 \\
\hline 1-Methyl-4-ethylbenzene & 30 & 45 \\
\hline 1,3,5-Trimethylbenzene & 30 & 45 \\
\hline 1,2,4-Trimethylbenzene & 35 & 45 \\
\hline 1-Methylnaphthalene & 75 & 100 \\
\hline Naphthalene & 60 & 100 \\
\hline
\end{tabular}

a Within the RSDs of the measurements.

TABLE 2

Calibration Data for Selected Aromatic Compounds with SPME

\begin{tabular}{lcccc}
\hline Compound & Slope & y-int. $^{\text {a }}$ & $\mathrm{R}^{2}$ & LDR \\
\hline & (A.U./ppb [wt/wt]) & & & (ppb [wt/wt]) \\
Benzene & $7.96 \mathrm{E}-5$ & $5.46 \mathrm{E}-3$ & $9.99 \mathrm{E}-1$ & $200-15600$ \\
Toluene & $5.89 \mathrm{E}-4$ & $2.40 \mathrm{E}-3$ & $9.99 \mathrm{E}-1$ & $30-4000$ \\
Ethylbenzene & $6.06 \mathrm{E}-4$ & $2.20 \mathrm{E}-3$ & $9.99 \mathrm{E}-1$ & $30-3500$ \\
$o-$ Xylene & $8.96 \mathrm{E}-4$ & $-1.97 \mathrm{E}-3$ & $9.99 \mathrm{E}-1$ & $30-1800$ \\
$m$-Xylene & $1.03 \mathrm{E}-3$ & $4.46 \mathrm{E}-3$ & $9.99 \mathrm{E}-1$ & $30-1700$ \\
p-Xylene & $1.68 \mathrm{E}-3$ & $2.57 \mathrm{E}-3$ & $9.99 \mathrm{E}-1$ & $20-900$ \\
1-Methyl-3- & $1.25 \mathrm{E}-3$ & $3.39 \mathrm{E}-4$ & $9.99 \mathrm{E}-1$ & $10-865$ \\
1-Methyl-4- & $1.55 \mathrm{E}-3$ & $4.60 \mathrm{E}-3$ & $9.99 \mathrm{E}-1$ & $10-860$ \\
$1,3,5-$ & $9.20 \mathrm{E}-4$ & $-1.67 \mathrm{E}-3$ & $9.99 \mathrm{E}-1$ & $20-250$ \\
$1,2,4-$ & $8.90 \mathrm{E}-4$ & $8.35 \mathrm{E}-4$ & $9.99 \mathrm{E}-1$ & $30-890$ \\
$1-$ Methylnaphthalene & $2.43 \mathrm{E}-2$ & $-2.30 \mathrm{E}-4$ & $9.99 \mathrm{E}-1$ & $1-40$ \\
& $1.36 \mathrm{E}-2^{\mathrm{b}}$ & $1.76 \mathrm{E}-4$ & $9.97 \mathrm{E}-1$ & $1-90$ \\
Naphthalene & $1.55 \mathrm{E}-2$ & $3.70 \mathrm{E}-3$ & $9.99 \mathrm{E}-1$ & $2-80$ \\
& $7.41 \mathrm{E}-3^{\mathrm{b}}$ & $9.28 \mathrm{E}-3$ & $9.94 \mathrm{E}-1$ & $1-90$ \\
\hline
\end{tabular}

a-int. corresponds to the y-axis intercept.

b Values were obtained with a 45 -min extraction. 
TABLE 3

Detection Limits of Selected Aromatic Compounds with and Without SPME

\begin{tabular}{llccc}
\hline & \multicolumn{4}{c}{ Detection Limit, ppb (wt/wt) } \\
\cline { 2 - 5 } Compound & w/o SPME (\% RSD) & \multicolumn{2}{c}{ w/SPME (\% RSD) $)^{\mathrm{a}}$} \\
\hline Benzene & 1300 & $(6.9)$ & 96.5 & $(6.9)$ \\
Toluene & 900 & $(5.6)$ & 10.0 & $(5.6)$ \\
Ethylbenzene & 900 & $(7.4)$ & 11.7 & $(6.0)$ \\
$o$-Xylene & 500 & $(3.0)$ & 7.80 & $(3.0)$ \\
$m$-Xylene & 800 & $(5.2)$ & 5.50 & $(5.2)$ \\
$p$-Xylene & 600 & $(9.1)$ & 5.50 & $(9.1)$ \\
1-Methyl-3-ethylbenzene & 928 & $(4.7)$ & 5.83 & $(4.7)$ \\
1-Methyl-4-ethylbenzene & 612 & $(4.2)$ & 3.68 & $(8.9)$ \\
1,3,5-Trimethylbenzene & 964 & $(9.8)$ & 8.24 & $(9.8)$ \\
1,2,4-Trimethylbenzene & 964 & $(12)$ & 8.08 & $(12)$ \\
1-Methylnaphthalene & 64.2 & $(7.9)$ & 0.412 & $(5.2)$ \\
& & & $0.814^{\mathrm{b}}$ & $(6.7)$ \\
Naphthalene & 65.3 & $(6.0)$ & 0.400 & $(6.0)$ \\
& & & $0.795^{\mathrm{b}}$ & $(7.0)$ \\
\hline
\end{tabular}

averages and relative standard deviations from triplicate measurements.

b These values were obtained with a 45 -min extraction.

detection of gasoline was quite poor. These poor detection limits achieved without the SPME step are a result of 1) no SPME preconcentration and 2) the high background UV absorbance from the polar matrix organics in these surface waters.

In contrast to the poor detection limits for fuels in surface waters using direct UV measurements, when the SPME/UV technique is used, the detection limits (as total fuel concentration in water) are in the low ppb $(\mu \mathrm{g} / \mathrm{L})$ range (Table 4). It is also interesting to note that the response of gasoline, jet fuel, and diesel fuels in water are very similar, despite the very different chemical compositions. These results indicate that the SPME/UV approach can yield reasonable quantitative information for fuel spills into water, even if the fuel composition is unknown. The reasons for this similarity in response despite the very different aromatic content of diesel fuel compared to the gasoline and jet fuels is presently being investigated.

Finally, the ability of SPME/UV to yield quantitative measurements was demonstrated with the two surface waters contaminated with the three test fuels. As shown in Table 5, the SPME/UV technique yielded total fuel concentrations within $87 \%$ to $106 \%$ of the known values.

Reproducibilities (RSDs) were also good for quantitative determinations. It must also be noted that 
the SPME/UV measurements required less than 1 hour and generated no solvent waste. In addition, the SPME sorbent chips are very inexpensive and are reuseable after a simple thermal cleaning step.

\subsection{Sorbent Evaluation and Construction of Simple and Robust Sorbent Coupons}

Additional evaluation of several different sorbent materials was performed in conjunction with Task 1.11. In addition, a simple and inexpensive method for constructing sorbent "dipsticks" by melting sorbent materials onto a wire mesh (e.g., window screen) has been developed in conjunction with Task 1.11. This method should allow a much wider variety of sorbent materials to be used for both UV and infrared spectroscopy. The method also allows different film thicknesses to be made and provides a physically robust device for the sorption of water and air samples. Please refer to the Semiannual Report for Task 1.11 for additional details.

\section{TABLE 4}

Detection Limits with and Without SPME for Various Fuels

\begin{tabular}{|c|c|c|c|c|c|c|c|}
\hline \multirow{3}{*}{ Fuel } & \multicolumn{7}{|c|}{ Detection Limit, ppb (wt/wt) } \\
\hline & \multicolumn{3}{|c|}{ Pond Water } & \multicolumn{3}{|c|}{ River Water } & \\
\hline & \multicolumn{2}{|c|}{$\begin{array}{l}\text { w/SPME } \\
(\% \mathrm{RSD})^{\mathrm{a}}\end{array}$} & $\begin{array}{c}\text { w/o SPME } \\
(\% \mathrm{RSD})^{\mathrm{a}}\end{array}$ & \multicolumn{2}{|c|}{$\begin{array}{l}\text { w/SPME } \\
(\% \text { RSD })^{a}\end{array}$} & \multicolumn{2}{|c|}{$\begin{array}{l}\text { w/o SPME } \\
(\% \text { RSD })^{a}\end{array}$} \\
\hline $\begin{array}{l}\text { Unleaded } \\
\text { Gasoline }\end{array}$ & 3.65 & $(12)$ & $7060(5.9)$ & 4.51 & $(5.1)$ & 3920 & $(6.7)$ \\
\hline JP4 & 14.5 & $(8.8)$ & $>100,000^{b}$ & 16.4 & (5.6) & $>100,000^{b}$ & \\
\hline \#1 Diesel & 8.35 & $(6.8)$ & $>100,000^{b}$ & 8.34 & $(4.8)$ & $>100,000^{\mathrm{b}}$ & \\
\hline
\end{tabular}

${ }^{a}$ Averages and relative standard deviations from triplicate measurements.

${ }^{b}$ Due to lack of spectral contrast, values were defined at solubility limit in water.

TABLE 5

Recovery Data for Unleaded Gasoline, JP4, and \#1 Diesel Fuel from Various Water Matrices

\begin{tabular}{lccc}
\hline Fuel & Water Matrix & \% Recovery $^{\mathrm{a}}$ & \% RSD \\
\hline Unleaded Gasoline & River & 105 & 9.9 \\
& Pond & 106 & 9.4 \\
JP4 & River & 95 & 10.3 \\
& Pond & 89 & 9.9 \\
\#1 Diesel & River & 87 & 5.0 \\
& Pond & 93 & 6.0 \\
\hline
\end{tabular}

a These values resulted from a single extraction of three separate analyte spiked water solutions.

Each fuel was spiked to a total concentration of $1 \mathrm{ppm}(1 \mathrm{mg} / \mathrm{L})$. 


\begin{tabular}{|c|c|c|c|}
\hline $\begin{array}{l}\text { 1. Program/Project Ident } \\
\text { DE-FC21-93MC30097 }\end{array}$ & $\begin{array}{l}\text { tification No. } \\
7\end{array}$ & $\begin{array}{l}\text { 2. Program/Project Titlo } \\
\text { TASK } 1.0 \text { WASTE MANAGEMENT }\end{array}$ & $\begin{array}{l}\text { 3. Reporting Period } \\
\text { 4-1-96 through } 6-30-96\end{array}$ \\
\hline \multirow[t]{2}{*}{ 4. Name and Address } & \multirow{2}{*}{\multicolumn{2}{|c|}{$\begin{array}{l}\text { Energy \& Environmental Research Center } \\
\text { University of North Dakota } \\
\text { PO Box } 9018 \text {, Grand Forks, ND } 58202-9018\end{array}$}} & $\begin{array}{l}\text { 5. Program/Project Start Date } \\
1-12-93\end{array}$ \\
\hline & & & $\begin{array}{l}\text { 6. Completion Date } \\
12-31-97\end{array}$ \\
\hline
\end{tabular}

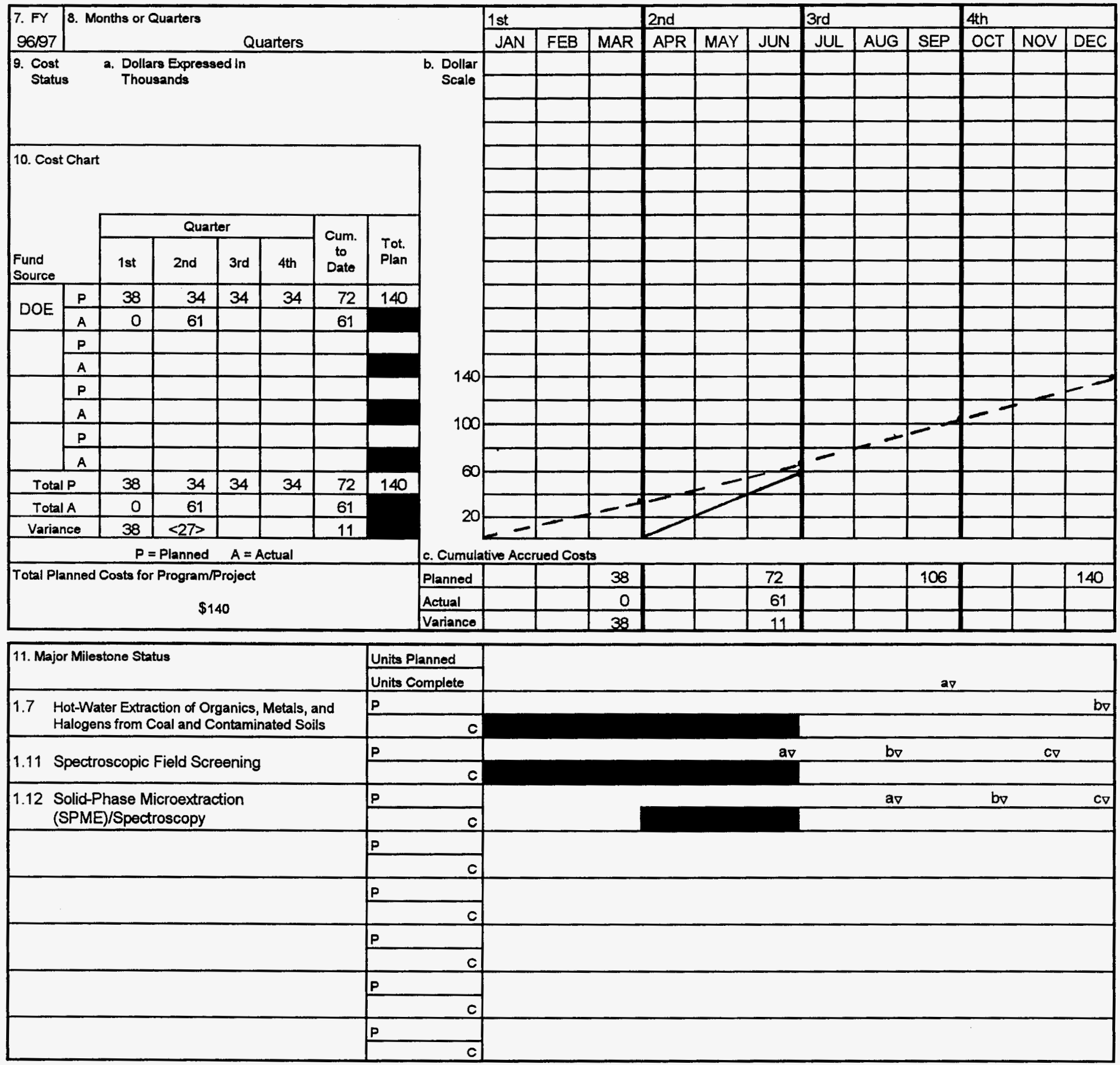

12. Remarks

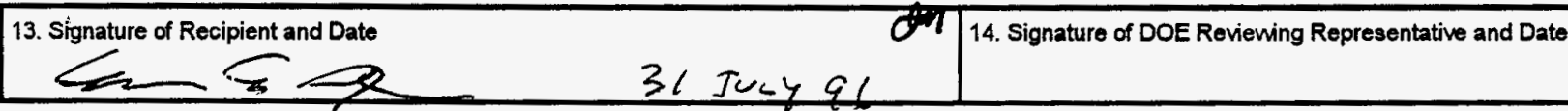




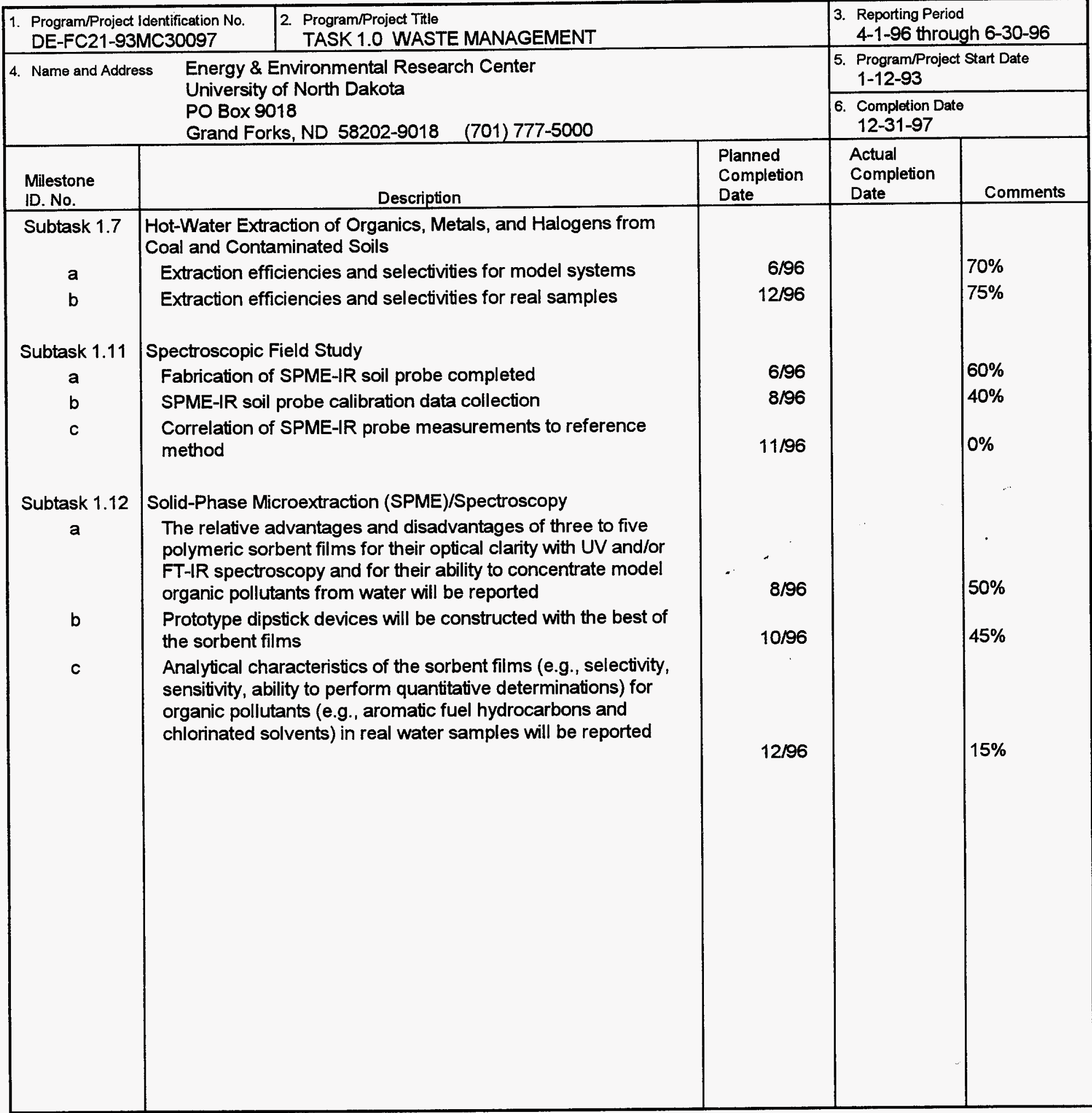


M97005429

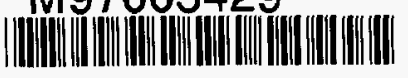

Report Number (14) DOE/MC/30097=-5708

subl. Date (11) 1996

sponsor Code (18) DQE/FE, XF

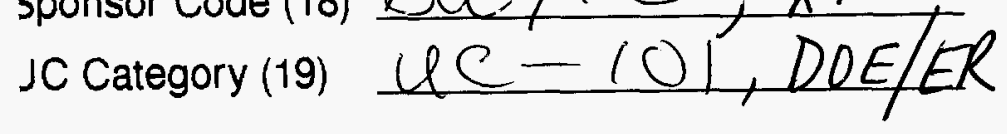

DOE 